
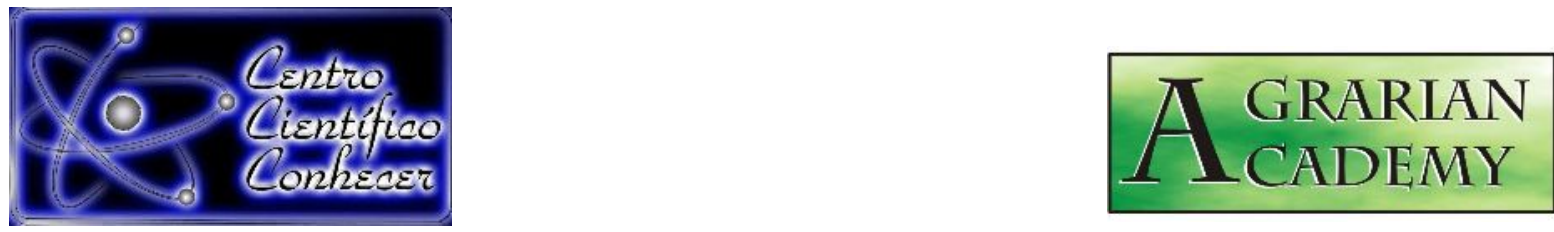

\title{
BANDEJAS, ADUBAÇÃO E IDADE DE TRANSPLANTIO NA FORMAÇÃO DE MUDAS DO MAXIXE PAULISTA
}

\author{
Cristovam Colombo Belfort;Francisco Alves de Souza Neto;Flávia da Silva \\ Soares;Pedro Emartino Bezerra Campelo;Larisse Rodrigues Lima da Silva
}

Engenheiro Agrônomo UFC, MSc. Fitotecnia UFV, DR. Agronomia ESALQ/USP, Docente do Curso de Agronomia UFPI, Prof. Titular Departamento de

Fitotecnia/CCA, E-mail: ccbelfor@yahoo.com.br, Orcid iD: https://orcid.org/00000001-8963-7179

Engenheiro Agrônomo UFPI, Secretaria de Agricultura de Aldeias Altas/Maranhão, : Orcid iD: https://orcid.org/0000-0003-1072-3934

Acadêmica de Agronomia da UFPI,Orcid iD: https://orcid.org/0000-0002-4454-8321

Acadêmico de Agronomia da UFPI,Orcid iD: https://orcid.org/0000-0002-9180-6178

Engenheira Agrônoma UFPI, Pró-Reitoria de Planejamento UFPI ,Orcid iD: https://orcid.org/ 0000-0003-4649-4109

Recebido em: 15/12/2021 - Aprovado em: 15/12/2021 - Publicado em: 30/12/2021
DOI: 10.18677/Agrarian_Academy_2021B3
trabalho licenciado sob licença Creative Commons Attribution-NonCommercial-NoDerivatives 4.0 International License.

\section{RESUMO}

No maxixe a produção de mudas não é uma tecnologia corrente. A expressividade do maxixe paulista justifica a adoção desta prática. Para tanto este trabalho foi conduzido em condição de telado com sombrite $50 \%$, no Centro de Ciências Agrárias da Universidade Federal do Piauí, em Teresina, entre Outubro e Dezembro de 2020. Objetivando avaliar o efeito de bandejas, adubação e idades das plântulas na formação de dias da semeadura (DAS), foram aferidos número de folhas, altura da planta, comprimento da raiz, massa fresca das folhas, caule e raiz de mudas do maxixe paulista cv. Gibão, foi conduzido um ensaio em delineamento experimental de blocos casualizados, com 4 repetições. Os tratamentos foram distribuídos em arranjo fatorial $2 \times 2 \times 3$, com os fatores tipo de bandeja (72 e 128 células), adubação (com e sem) e idades de transplantio (20, 24 e 29 DAS), utilizando o substrato Bioadubo enriquecido com $3 g$ da fórmula 4-14-8/L de mistura. Avaliaram-se altura da planta, profundidade da raiz, massa fresca da parte aérea e da raiz. Tipo de bandeja e idade influenciaram na qualidade das mudas, onde plântulas oriundas de bandejas de 72 células apresentaram maior altura, raízes mais profundas e maior massa fresca da parte aérea, sobretudo quando avaliadas aos 29 DAS; constatou-se que é possível transplantar mudas de bandejas com 128 células, desde que aos 24 DAS. PALAVRAS-CHAVE: Cucumis anguria L; Idade de transplantio; Propagação. 


\title{
TRAYS, FERTILIZATION AND TRANSPLANTING SEEDLINGS AGE IN THE PAULISTA FORMATION
}

\begin{abstract}
In the gherkin, the production of seedlings is not a current technology. The expressiveness of the paulista gherkin justifies the adoption of this practice. For this purpose, this work was carried out in a greenhouse condition with $50 \%$ shade, at the Center for Agricultural Sciences of the Federal University of Piauí, in Teresina, between October and December 2020. Aiming to evaluate the effect of trays, fertilization and seedling ages in the formation number of leaves, plant height, root length, fresh mass of leaves, stem and root of gherkin seedlings cv. Gibão, a trial was conducted in a randomized block design, with 4 replications. The treatments were distributed in a 2x2x3 factorial arrangement, with the factors of tray type (72 and 128 cells), fertilization (with and without) and transplanting ages (20, 24 and 29 DAS), using the Biofertilizer substrate enriched with $3 \mathrm{~g}$ of the formula $4-14-8 / \mathrm{L}$ of mix. Plant height, root depth, shoot and root fresh weight were evaluated. Type of tray and age influenced the quality of seedlings, where seedlings from trays of 72 cells showed greater height, deeper roots and greater fresh mass of aerial part, especially when evaluated at 29 DAS; it was found that it is possible to transplant seedlings from trays with 128 cells, as long as at 24 DAS.
\end{abstract}

KEYWORDS: Cucumis anguria L; Transplant age; Propagation;

\section{INTRODUÇÃO}

O Maxixe Paulista é um novo tipo de maxixe desenvolvido na ESALQ/USP, derivado do cruzamento de cultivares de (Cucumis anguria var. anguria) e (Cucumis anguria var. longaculeatus), com características distintas de fruto e folhas. Seus frutos apresentam massa média acima de $70 \mathrm{~g}$ e ausência de espiculosidade com folhas não lobuladas, semelhantes às de pepino (MODOLO et al., 1999). A ausência de espiculosidade proporciona facilidade no manuseio e maior aproveitamento do fruto, pois este pode ser consumido com casca. A produção de mudas se tornou prática indispensável na olericultura, pelo menor desperdício de sementes, pelo elevado preço, sobretudo, quando adotados os híbridos. A utilização de mudas em confronto com a semeadura direta resulta em precocidade da cultura no campo, estande mais uniforme facilitando a aplicação dos insumos, diminui a competição inicial com plantas daninhas com reflexo direto na produtividade (GODOY, 2007).

$\mathrm{Na}$ produção de mudas, além da necessidade física de suporte, desponta também a exigência de uma fonte inicial de nutrientes para as futuras plantas. Este meio pode ser desprovido de nutrientes desde que exista uma outra fonte nutricional. A idade das mudas é um importante fator a ser estudado sendo determinante na seleção do material propagativo, até porque a idade avançada em que as mudas vêm sendo transplantadas pode prejudicar a sua qualidade, com redução do desenvolvimento e da produção (BELFORT; GOMES, 2000; BELFORT et al, 2005; SALATA et al., 2011).

A produção de mudas em toda a família Cucurbitaceae evoluiu muito recentemente, sendo o uso de bandejas de poliestireno expandido a prática mais comum. Além disso, as bandejas utilizadas facilitam o transporte das mudas, possibilitado a sua reutilização, além de causar menores danos às raízes por ocasião do transplante (MINAMI, 1995; BORNE, 1999; PEREIRA; MARTINEZ, 1999). 
O uso de bandejas com maior número de células pode ser mais vantajoso economicamente, produzindo maior número de mudas em menor área, com menor gasto de substrato por muda, contudo pode haver prejuízo na produção final e em termos qualitativos, devido à competição por luz e espaço físico ao qual a planta fica submetida (PURQUERIO et al., 2003). A importância da produção de mudas no cultivo de hortaliças e as tendências cada vez mais fortes de modernização desta atividade, envolvendo variados tipos de bandejas existentes no mercado, bem como das especificidades de cada espécie vegetal em resposta a um volume de substrato e nutrição mineral, faz-se necessário observar o efeito desses fatores nesta espécie até então pouco investigada.

Mais modernamente a partir do suporte da Genética com o surgimento do Maxixe Paulista e do advento do cultivo protegido, a produção de mudas passou a figurar na agenda de novas práticas culturais. Nesta linha de raciocino foram testados copos de jornal e substratos diversos (CARDOSO et al., 2012), bem como adotadas as bandejas de poliestireno de 72 células no processo produtivo (MODOLO; COSTA, 2000). Nos diversos casos sem uma definição do melhor momento para realizar o transplantio para o campo o qual pode ocorrer em até 47 dias após a semeadura (MODOLO; COSTA, 2003) e do recipiente mais adequado, tendo em vista que as espécies desta família não reagem favoravelmente a traumas no sistema radicular, não tolerando a formação de mudas em raiz nua (ANJOS et al., 2003).

O presente trabalho teve por objetivo avaliar no maxixe paulista, os efeitos de dois tipos de bandejas e adubação do substrato, em três idades, na fase plantular.

\section{MATERIAL E MÉTODOS}

A pesquisa foi conduzida na unidade de cultivo protegido do Departamento de Fitotecnia do Centro de Ciências Agrárias, na Universidade Federal do PiauíUFPI, construída com tela de vinil preto, com 50\% de sombreamento, realizada no período de outubro a dezembro de 2020. O delineamento experimental foi em blocos casualizados com 4 (quatro) repetições e os tratamentos dispostos em arranjo

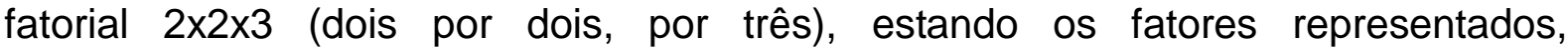
respectivamente, por tipo de bandeja (B1=72; $B 2=128$ células), adubação (com e sem adubação) e a idade das plantas (transplantio aos 20(vinte), 24 (vinte e quatro) e 29 (vinte e nove)) dias após a semeadura (DAS), distribuídas em parcelas de 12 (doze) células. A adubação foi aplicada na dose de $3 \mathrm{~g}$ (três gramas) da fórmula 414-8 (quatro-quatorze-oito), por litro de substrato orgânico comercial Pole. Utilizaram-se sementes do Maxixe Paulista cultivar Gibão, sendo avaliadas as variáveis: Altura da planta, medida do colo à gema apical, comprimento da raiz, peso da matéria fresca da parte aérea e da raiz, as variáveis em questão foram avaliadas durante o transplantio.

Os dados foram analisados pelo programa estatístico ASSISTAT (FERREIRA, 2011), os resultados foram obtidos, e as médias comparadas pelo teste de Tukey a $5 \%$ de probabilidade.

\section{RESULTADOS E DISCUSSÃO}

De acordo com a Tabela 1, verifica-se que as bandejas com 72 (setenta e duas) células promoveram a formação de mudas com maior altura, quando comparadas às plantas provenientes de bandejas com 128 (cento e vinte e oito) 
células. Segundo observações de Cardoso et al. (2012) mudas de maxixe comum cultivadas em copos de jornal de $500 \mathrm{~mL}$ aos 15 (quinze) dias após a emergência apresentaram altura em torno de $2,70 \mathrm{~cm}$, muito inferior ao obtido no ensaio em tela. Mudas de abobrinha provenientes de bandejas com 72 (setenta e duas) células foram maiores que as plantas colhidas nas bandejas de 128 (cento e vinte e oito), fenômeno que pode ser atribuído às melhores condições para o crescimento do sistema radicular em decorrência do maior espaço (BRITO, 2005) e por consequência aumentando a área de contato da raiz com o substrato, permitindo a absorção de água e melhor aproveitamento dos nutrientes neste contidos (MORSELLI, 2009). Resultados similares foram obtidos por Purquerio et al. (2003) que, ao estudarem o comportamento da rúcula em diferentes datas após a semeadura constataram melhor desenvolvimento nas bandejas com maior capacidade volumétrica, em todas as datas avaliadas. De qualquer sorte, nestas circunstâncias a adubação não influenciou na altura das plantas (Tabela 1). Acerca da idade, diferenças quanto a este parâmetro eram aguardadas, sobretudo entre os extremos, até porque trata-se do natural processo de acumulação de matéria fresca na planta.

O crescimento e desenvolvimento de plântulas da família Cucurbitaceae dependem da atividade fotossintética das folhas cotiledonares (PENNY et al., 1976). Tal comportamento conforme mencionam Bisognin et al. (2004) traz vantagens adaptativas em relação as espécies cujos cotilédones apresentam tão somente a função de reserva, dificultando a rápida emissão de folhas verdadeiras para iniciar a produção de fotoassimilados.

TABELA 1 - Médias referentes à altura, profundidade da raiz, massa fresca da parte aérea e raiz de plântulas de maxixe Gibão em função de bandeja, adubação e idade. Teresina, 2020.

Fatores

Parâmetros

\begin{tabular}{cccc}
\hline Bandejas & Altura & Profundidade & Parte aérea \\
\hline B1 & $11,93 \mathrm{a}$ & $7,12 \mathrm{a}$ & $1,27 \mathrm{a}$ \\
B2 & $7,83 \mathrm{~b}$ & $5,83 \mathrm{~b}$ & $0,66 \mathrm{~b}$ \\
\hline Adubação & & & \\
\hline Com & $10,12 \mathrm{a}$ & $6,66 \mathrm{a}$ & $1,02 \mathrm{a}$ \\
Sem & $9,19 \mathrm{a}$ & $6,30 \mathrm{a}$ & \\
\hline Idade & & & $0,92 \mathrm{a}$ \\
\hline 1 & $8,35 \mathrm{~b}$ & $5,55 \mathrm{~b}$ & $0,83 \mathrm{~b}$ \\
2 & $9,50 \mathrm{~b}$ & $6,76 \mathrm{~b}$ & $1,25 \mathrm{~b}$ \\
\hline 3 & $11,12 \mathrm{a}$ & $7,13 \mathrm{a}$ &
\end{tabular}

Médias seguidas pela mesma letra na coluna não diferem significativamente entre si, pelo teste de Tukey, a 5\% de probabilidade

Houve efeito positivo do tipo de bandeja e da idade de transplantio na profundidade da raiz (Tabela 1), não sendo observada influência da adubação na característica avaliada, similarmente ao que aconteceu para o parâmetro altura. Plântulas semeadas em bandejas com 72 (setenta e duas) células apresentaram maior profundidade do sistema radicular superando aquelas obtidas em bandejas de 
128 (cento e vinte e oito) células em 18\%, muito embora não tenham atingido o limite máximo da bandeja que é $12,0 \mathrm{~cm}$. Tais resultados encontram suporte nas observações de Belfort et al. (2020) os quais verificaram que, no melão Caipira, à altura e comprimento da raiz, variam, independentemente do tipo de bandeja e ambiente. Plântulas de ambiente fechado e bandejas de 72 (setenta e duas) células são maiores, comportamento que se repete na aferição de estádio de crescimento e ambiente, onde as plântulas obtidas em bandejas de 72 (setenta e duas) células apresentaram maior massa fresca da parte aérea.

Efetivamente, apenas tipos de bandejas e idade das mudas exerceram influência no peso da matéria fresca da parte aérea, acentuando a superioridade das bandejas de 72 (setenta e duas) em relação às de 128 (cento e vinte e oito) células e do maior peso médio daquelas produzidas aos 29 (vinte e nove) dias após a semeadura (Tabela 2). Acerca da ausência de resposta para adubação é possível atribuir-se à qualidade do substrato utilizado acrescida às pequenas exigências nutricionais nesta fase de vida da planta.

A superioridade das plantas obtidas em bandejas com 72 (setenta e duas) células quanto ao peso da matéria fresca da parte aérea, ultrapassou $42 \%$ em relação àquelas obtidas em bandejas com 128 (cento e vinte e oito) unidades, independentemente do fator adubação, com registro de interação significativa entre o fator tipo de bandeja e idade da muda (Tabela 2). Salvo para alguns substratos, bandejas de 72 (setenta e duas) células propiciam a formação de maior massa seca da parte aérea em mudas de melancia, conforme observado por Souza et al. (2004).

TABELA 2 - Médias referentes à altura, profundidade da raiz, massa fresca da parte aérea e raiz de plântulas de maxixe Gibão em função de bandeja, adubação e idade. Teresina, 2020.

Fatores

Parâmetros

\begin{tabular}{cccc}
\hline Bandejas & Altura & Profundidade & Parte aérea \\
\hline B1 & $11,93 \mathrm{a}$ & $7,12 \mathrm{a}$ & $1,27 \mathrm{a}$ \\
B2 & $7,83 \mathrm{~b}$ & $5,83 \mathrm{~b}$ & $0,66 \mathrm{~b}$ \\
\hline Adubação & & & \\
\hline Com & $10,12 \mathrm{a}$ & $6,66 \mathrm{a}$ & $1,02 \mathrm{a}$ \\
Sem & $9,19 \mathrm{a}$ & $6,30 \mathrm{a}$ & $0,92 \mathrm{a}$ \\
\hline Idade & & & \\
\hline 1 & $8,35 \mathrm{~b}$ & $5,55 \mathrm{~b}$ & $0,83 \mathrm{~b}$ \\
2 & $9,50 \mathrm{~b}$ & $6,76 \mathrm{~b}$ & $0,84 \mathrm{~b}$ \\
3 & $11,12 \mathrm{a}$ & $7,13 \mathrm{a}$ & $1,25 \mathrm{a}$ \\
\hline
\end{tabular}

Médias seguidas pela mesma letra na coluna não diferem significativamente entre si, pelo teste Tukey, a $5 \%$ de probabilidade.

Plântulas colhidas nas bandejas com 72 (setenta e duas) células, em qualquer idade apresentaram maior massa fresca quando comparadas às obtidas em bandejas de 128 (cento e vinte e oito). Examinado o fator bandeja dentro de idade, foi constatada diferença apenas quando consideradas as bandejas maiores, algo em torno de 55,00 \%. Piovesan e Cardoso (2009) avaliando a qualidade da produção de abóbora em função de tipos de bandejas e diferentes idades de AGRARIAN ACADEMY, Centro Científico Conhecer - Jandaia-GO, v.8, n.16 P. 36 2021 
transplante não observaram interação entre idade e tipo de bandeja, concluindo na oportunidade que, quanto maior a idade das mudas menor o comprimento, o diâmetro e a massa média dos frutos.

Belfort et al. (2005) verificaram que as bandejas com 72 (setenta e duas) células propiciaram um melhor desenvolvimento tanto da parte aérea como do sistema radicular das mudas de melancia. É provável que, no presente caso, o sistema radicular já se aproximava do limite inferior da bandeja, na faixa de transição onde a raiz, por impedimento, inicia o processo de restrição no crescimento ocorrendo aí um aumento na sua densidade, fato que, contraria em princípio as observações dos autores citados, sendo decorrente do aprofundamento em bandejas maiores quando o sistema radicular não ultrapassou os $7,13 \mathrm{~cm}$.

É oportuno arrolar para reflexão o custo das mudas, uma vez considerados o volume do substrato, o número de mudas produzidas por bandeja e a própria operacionalidade decorrente, complementando com as observações de Seabra Júnior et al. (2004) nas quais afirmam que nem sempre mudas com maior número de folhas e maior massa fresca, na fase de transplante, resultam em maior produção comercial. Ao mesmo tempo nem sempre uma muda avaliada como excelente no momento do transplante é a que resultará em maior potencial produtivo (SALATA et al., 2011).

TABELA 3 - Médias referentes ao peso da massa fresca da parte aérea de plântulas de Maxixe Gibão em resposta à interação entre bandeja e idade. Teresina, 2020.

\section{Fatores Parâmetros}

\begin{tabular}{cccc}
\hline Bandejas & Altura & Profundidade & Parte aérea \\
& & & $1,27 \mathrm{a}$ \\
B1 & $11,93 \mathrm{a}$ & $5,83 \mathrm{a}$ & $0,66 \mathrm{~b}$ \\
B2 & $7,83 \mathrm{~b}$ & & \\
\hline Adubação & & $6,66 \mathrm{a}$ & $1,02 \mathrm{a}$ \\
& $10,12 \mathrm{a}$ & $6,30 \mathrm{a}$ & $0,92 \mathrm{a}$ \\
\hline Com & $9,19 \mathrm{a}$ & & \\
Sem & & $5,55 \mathrm{~b}$ & $0,83 \mathrm{~b}$ \\
Idade & $8,35 \mathrm{~b}$ & $6,76 \mathrm{~b}$ & $0,84 \mathrm{~b}$ \\
\hline 1 & $9,50 \mathrm{~b}$ & $7,13 \mathrm{a}$ & $1,25 \mathrm{a}$ \\
\hline 3 & $11,12 \mathrm{a}$ & &
\end{tabular}

Médias seguidas pela mesma letra na coluna não diferem significativamente entre si, pelo teste Tukey, a $5 \%$ de probabilidade.

Para o maxixe gibão, a utilização de bandejas de 72 (setenta e duas) células propicia a formação de mudas com maior altura, e raízes mais profundas e com maior peso da matéria fresca da parte aérea. Ao mesmo tempo plântulas avaliadas aos 29 (vinte e nove) dias após a semeadura, apresentam maior altura, incrementos respectivos de $55 \%$ no peso de massa fresca da raiz e $65 \%$ da parte aérea com relação às plantas com 24 (vinte e quatro) dias. De um modo geral a adubação não interferiu nos resultados. As plantas reagiram favoravelmente à produção de mudas através de bandejas e, balizados os custos e algumas variações encontradas, é possível elencar como alternativa o uso de bandejas de 128 células, sobretudo se houver uma antecipação no transplantio para os 24 DAS. 


\section{CONCLUSÕES}

A produção de mudas de maxixe paulista em bandejas constitui-se numa alternativa viável, com maior desempenho para as bandejas com 72 (setenta e duas) células. Nestas, o transplantio pode ser realizado até os 29 (vinte e nove) DAS, independentemente da adubação. Balizados os custos e momento da operação, as bandejas de 128 (cento e vinte e oito) células poderão ser cogitadas com a antecipação no transplantio para 24 (vinte e quatro) DAS.

\section{REFERENCIAS}

ANJOS J.B; LOPES P.R.C; FARIA C.M.B; COSTA N.D. 2003. Preparo e conservação do solo, calagem e plantio. In: SILVA H.R; COSTA N.D (eds). Melão produção. Brasília, DF: Embrapa Informação Tecnológica. p. 35-39. (Frutas do Brasil, 33).

BELFORT, C.C.; GOMES, M.S.F.D. Avaliação da idade de transplantio para mudas de melancia. Horticultura Brasileira, Brasília, v.18, p.468-469, jul. 2000.

BELFORT, C.C.; RODRIGUES, G.M.; BARBOSA NERY, E.B.; SETÚBAL, J.W.; THÉ, F.W.; et al.; Desempenho de mudas de melancia obtidas em dois tipos de bandejas, em quatro estágios de crescimento, com e sem adubação. Horticultura Brasileira, Brasília, DF, v.23, n.2, ago. 2005.

BELFORT, C.C.; NERY, E. B.; CAMPELO, P. E. B.; QUEIROZ NETO, A. P.; GOMES, J. P.; et al.;Respostas ecofisiológicas de plântulas de melão sob cultivo protegido e a céu aberto. Research, Society and Development, v. 9, n. 9, e776997888, 2020 (CC BY 4.0) | ISSN 2525-3409 | DOI: http://dx.doi.org/10.33448/rsd-v9i9.7888

BISOGNIN, D. A.; AMARANTE, C. V. T.; DELLAI, J. Contribuição das folhas cotiledonares para o crescimento e estabelecimento de plântulas de cucurbitáceas. Horticultura Brasileira, Brasília, v.22, n.2, p.309-313, abril-junho 2004.

BORNE, H.R. Produção de mudas de hortaliças. Guaíba: Agropecuária, 1999. $187 \mathrm{p}$.

BRITO A. B. Influência de tipos de bandejas, estádios de crescimento e adubação química, no desempenho de mudas de abobrinha (Cucurbita pepo L.). Universidade Federal do Piauí, Dissertação de Mestrado. 2005. 33 p.

CARDOSO M.O; OLIVEIRA M.L; VASCONCELOS H.S; BERNI, R.F. 2012. Substrato artesanal para produção de mudas de maxixe por olericultores familiares no Estado do Amazonas. Horticultura Brasileira 30: S3196-S3202.

FERREIRA, D. F. (2011). Sisvar: a computer statistical analysis system. Ciência e Agrotecnologia, Lavras, v. 35, n. 6. pp 1039-1042, 2011.

GODOY, W.I. Avaliação de substratos alternativos para a produção de mudas de tomateiro. Revista Brasileira de Agroecologia, v.2, n. 2, out. 2007.

MINAMI, K. Mudas hortícolas de alta qualidade. In: Produção de mudas de alta qualidade em horticultura. São Paulo: T.A. Queiroz, 1995. p.19-27. 
MODOLO, V.A.; COSTA, C.P. Avaliação de linhagens de maxixe paulista cultivadas em canteiros com cobertura de polietileno. Horticultura Brasileira, Brasília, v. 21, n. 3, p. 534-538, julho-setembro 2003.

MODOLO, V.A.; COSTA, C.P. Caracterização de frutificação e ponto de colheita em maxixe. Horticultura Brasileira, Braslia, v. 18, Suplemento, p. 476-478, 2000.

MODOLO, V.A.; COSTA, C.P.; TESSARIOLI NETO, J. Caracterização de linhagens melhoradas de maxixe. In: CONGRESSO BRASILEIRO DE OLERICULTURA, 39, 1999, Tubarão. Anais... Tubarão: SBO, 1999, p. 201.

MORSELLI, T.B.G.A. Resíduos orgânicos em sistemas agrícolas. Ed. e Gráfica UFPel. Pelotas, RS. 2009, 228p.

PENNY, M. G.; MOORE, K. G.; LOVELL, P.H. The effect of inihibition of cotyledon photosynthesis on seedling development in Cucumis sativus L. Annual Botany, v.40, p.815-824, 1976.

PEREIRA, P.R.G.; MARTINEZ, H.E.P. Produção de mudas para o cultivo de hortaliças em solo e hidroponia. Informe Agropecuário, Belo Horizonte, v.20, n.200/201, p.24-31, 1999.

PIOVESAN, M.F; CARDOSO, A.I.I. Produção e qualidade de abóbora em função da idade das mudas e tipo de bandeja. Bragantia, Campinas, v.68, n.3, p.651-656, 2009

PURQUERIO, L.F; CARNEIRO JÚNIOR, A.G; GOTO, R. Tipos de bandejas e número de sementes por célula sobre o desenvolvimento e produtividade de Rúcula. Horticultura Brasileira, Brasília, DF, v. 22, n. 2, jul. 2003.

SALATA, A.C.; HIGUTI, A.R.O.; GODOY, A.R.; MAGRO, F.O.; CARDOSO, All. Produção de abobrinha em função da idade das mudas Ciência Agrotécnica., Lavras, v. 35, n. 3, P. 511-515, Maio/Jun., 2011

SEABRA JÚNIOR, S; GADUM, J.; CARDOSO, I.I. Produção de pepino em função da idade das mudas produzidas em recipientes com diferentes volumes de substrato. Horticultura Brasileira, Brasília, v.22, n.3, p.610-613, jul./set. 2004.

SOUZA, J. O.; GRANGEIRO, L. C.; BEZERRA, NETO F.; BARROS, JUNIOR, A. P.; NEGREIROS, M. Z.; et al.,,Produção de Mudas de Melancia em Bandejas sob Diferentes Substratos. Horticultura Brasileira, Brasília, v.22, n.3, jul./set. 2004. 